\title{
Expulsion of a Spontaneously Broken Arm of a T- Shaped IUD: a Case Report
}

\author{
Gulsum Uysal* \\ Department of Obstetrics and Gynecology, Adana City Education and Research Hospital, Adana, Turkey
}

*Corresponding Author: Gulsum Uysal (MD), Department of Obstetrics and Gynecology, Adana City Education and Research Hospital, Adana, Turkey, Email: gulsumaykut@yahoo.com

\begin{abstract}
Intrauterine device (IUD) is a safe, effective and worldwide used contraceptive method with side effects such as dysmenorrhoea, abdominal pain, displacement and perforation. However, spontaneous IUD fracture was rarely occurred during usage. We aimed to present a case of spontaneously broken arm of a Tshaped IUD with spontaneous expulsion during menstruation in a 32-year-old woman 3.5 years after insertion. She applied to our clinic due to finding of a foreign body in her pad. In situ copper T IUD was seen through transvaginal ultrasonography (TVUSG) and echogenicity of right transverse arm could not identified clearly. A pelvic graphy was performed to visualize clearly. She had normal blood test count with a negative pregnancy test. An alligator forceps were used for removal of IUD without threads.
\end{abstract}

This rare occurrence can come to mind when missing part of removed IUDs are not found after examinations. The arms of T shape IUDs should be ultrasonographically observed during routine controls. Frameless IUDs can be used instead of T shaped copper IUDs to decrease the complications of this " $T$ "shape. New shape of intrauterine contraceptive options should be offered to the patient and each patient should be taught their own examination and control.

Keywords: Broken Intrauterine Device, Expulsion, Frameless Intrauterine Devices, Contraception

\section{INTRODUCTION}

Intrauterine devices (IUDs) remain highly effective, reversible family planning methods in developing countries [1]. Intrauterine devices may cause some local side effects such as dysmenorrhoea, abdominal pain, uterine bleeding, perforation, displacement and infection $[1,2]$. There are also various complications such as migration to adjacent organs or omentum $[2,3]$. Here, we report a case of expulsion of a part of a spontaneously broken IUD in T shape.

IUDs are still the most common family planning method in our country because of the low cost, long lasting protection, lack of systemic side effects [2,4]. However, there are several complications mentioned above. IUDs may be dislocate in $5 \%$ of cases and eject spontaneously with a rate of 1:53 especially in first menstruation after insertion [5]. This expulsion rate decreases proportionally with age and parity.

\section{CASE REPORT}

A 32 year old Gravida 3, Parity 3, Abortion 0, Live 2, women admitted with a part of broken frame of her IUD to our clinic in August 2016
(Figure 1). During her menstruation period she noticed the broken part of the IUD in her pad. Therefore she applied to the clinic to check the localization of IUD. She had neither anormal bleeding symptoms nor pelvic pain. She had soft abdomen, with normal vital findings (afebrile, 120/80 mmhg). She had an Copper T A380 IUD, inserted three and a half year ago during lactation. Her last birth was cesarean section nearly 4 years ago. She had one normal delivery and two cesarean section. This IUD was her second use in her reproductive family planning life. She was pleased with this contraception method. Her body mass index was 22 and had no chronic disease or drug use.

In her per-speculum examination there was no thread of IUD. Following ultrasonography examination an in situ uterine cavited IUD was seen. The position of the uterus was anteverted (cervix angles forward) anteflexed (body is flexed forward) with endometrial thickness of 6 millimeters. An X-ray of her abdomen was performed and finally copper-T was revealed in the pelvic area of her abdomen with the shape of one side broken frame IUD (Figure 1). 


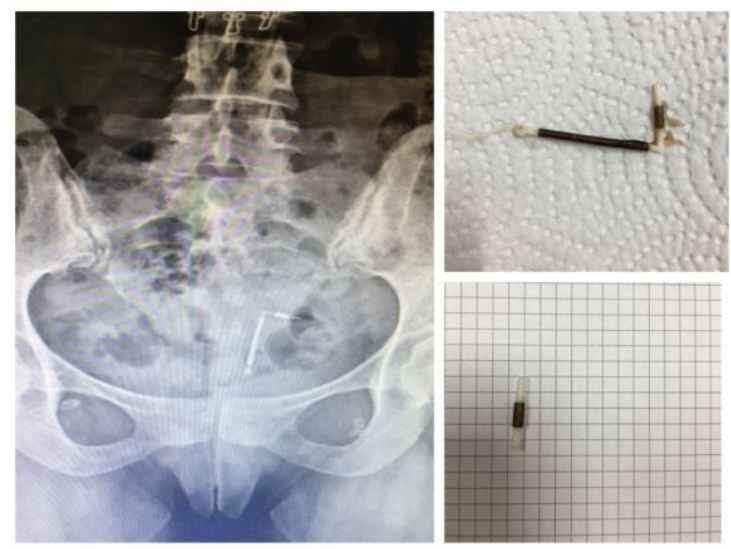

Figure1. Part of broken frame, shape of one side broken frame IUD in pelvic $x$-ray and IUD after removal

In laboratory, she had normal blood test count (hemoglobin count of $12.6 \mathrm{~g} / \mathrm{dL}$, white blood cell count of $6.9 \times 103 / \mathrm{uL}$, platelet count of $450 \times$ $103 / \mathrm{uL}$, with a negative pregnancy test (betahCG (total hCG) $<0.1 \mathrm{mIU} / \mathrm{mL}$ ) .

After her informed consent removal of IUD was planned. The one side broken frame IUD was removed successfully by GU with the help of a alligator forceps without anesthesia in gynecology clinic (Figure 1). There was no complication. The patient did well and was sent home at the same day.

\section{Discussion}

Spontaneous breakage of the arms of the IUD is a very rare occurrence. There are reported cases of the breakage of the arms of the IUD while attempting removal [6-8]. There is only one case about spontaneous expulsion of both arms ( fracture to the $\mathrm{T}$ junction) of a broken IUD, and one case of a spontaneous fracture and vaginal expulsion of the arm in a dislocated IUD [7,8]. But we found no reported cases of spontaneous expulsion of one arm of the frame of located in situ $\mathrm{T}$ shape IUD without any threads in the literature reviewed. It was removed succesfully with an alligator forceps.

One explanation for the breakage could be an initial stress fracture to the frames of IUD during insertion[9]. Moreover, rhythmic uterine contractions and menstrual bleeding at the time of her period might have been an additive stress on the frames of the IUD which probably led the breakage and self-ejection of one arm of the IUD. The patient was lucky to realize the broken part. Unnecessary research and treatment such as hysterescopy or even laparoscopy could be needed to find the broken part. This would also cause the surgeon anxious as to where the broken part of the IUD was.
An ultrasound screening is usually recommended first line examination to control the location of IUD $[1,2]$. The frames or strings of device may not be visualised during ultrasound examination in misplaced lost IUDs. Plain anteroposterior abdominal radiography is usually performed secondly to verify the presence of an IUD in the pelvis $[1,2]$. On the other hand frames of $T$ shape IUDs unfit the uterine cavity of some patients and cause clinically discomfort such as dysmenorrhea or pelvic pain [10,11]. The absence of a frame is particularly advantageous in these women. Frameless IUD, contains a very small copper, is smaller than any other IUD and better tolerated with less effect on the amount of blood loss [10-13].

Although the idea of inserting a foreign device into the uterine cavity is not new, IUDs are still the most essential and safe method for contraception. Regarding patients' medical and reproductive needs, new types of IUDs (frameless) were developed. Frameless IUDs may provide more options, benefits and less side effects and complications with the help of technologic advances.

In conclusion, new shape of intrauterine contraceptive options should be offered to the patient and each patient should be taught their own examination and control. After any type of IUD insertion ultrasonography should be routinely performed in the follow up of the patients.

\section{REFERENCES}

[1] Caliskan E, Ozturk N, Dilbaz BO, Dilbaz S. Analysis of risk factors associated with uterine perforation by intrauterine devices. Eur $\mathbf{J}$ Contracept Reprod Health Care. 8(3), 150 (2003).

[2] Uysal G, Nazik H, Tanridan Okçu N, Seyfettinoglu S, Kazgan H. Surgical Removal of an Extrauterine Device Migrating to Appendix. Case Rep Med. (4732153) (2016).

[3] Kaislasuo J, Suhonen S, Gissler M, Lähteenmäki $\mathrm{P}$, Heikinheimo O. Uterine perforation caused by intrauterine devices: clinical course and treatment. Hum Reprod. 28(6), 1546 (2013).

[4] Cwiak C, Cordes S. Postpartum intrauterine device placement: a patient-friendly option. Contracept Reprod Med. 15(3), 3 (2018).

[5] Zighelboim I., Szczedrin W. and Zambrano O. Management of IUD users with non-visible threads. Advances in Contraception. 6(2), 91 (1990).

[6] Mohanty K. Breakage of arm of Multiload intrauterine device during removal. Int J STD AIDS. 20(7), 512 (2009). 
[7] Sinha P, Pradhan A, Diab Y. Expulsion of part of a spontaneously broken IUCD Journal of Obstetrics and Gynaecology. 24(7), 837 (2004).

[8] Mutlu I, Mutlu MF, Guler I, Erdem A, Erdem M. Spontaneous Fracture and Vaginal Expulsion of the Arm of Intra-Uterine Device: Case Report. J Clin Anal Med. 6(6), 880 (2015).

[9] Goldstuck ND, Hofmeyr GJ, Sonnendecker EW, Buchart A. In vitro study of fracture forces associated with the Copper 7, Nova T and MLCu 250/375 intrauterine devices. Contraception. 41, 583 (1990).

[10] Wildemeersch D, Batar I, Gholade BA, et al. Gynefix: The intra-uterine contraceptive implantan update for interval, emergency and interval contraception. The British Journal of Family Planning. 24, 149 (1999).

[11] Van Kets H, Vrijens M, Van Trappen y, et al. The Gynefix intrauterine implant: a major Improvement in efficacy, expulsion and tolerance. Adv Contracept. 11(2), 131 (1995).

[12] Karateke A, Turgut A, Özdamar Ö, Wildemeersch D. Intra-cesarean insertion and fixation of frameless intrauterine devices. Turk $\mathbf{J}$ Obstet Gynecol. 14(1), 64 (2017).

[13] Goldstuck ND. Dimensional analysis of the endometrial cavity: how many dimensions should the ideal intrauterine device or system have? Int J Womens Health. 9(10), 165 (2018).

Citation: Gulsum Uysal, Expulsion of a Spontaneously Broken Arm of a T-Shaped IUD: a Case Report. ARC Journal of Public Health and Community Medicine.2018; 3(2):28-30. DOI: dx.doi.org/ 10.20431/24560596.0302005

Copyright: () 2018 Authors. This is an open-access article distributed under the terms of the Creative Commons Attribution License, which permits unrestricted use, distribution, and reproduction in any medium, provided the original author and source are credited. 